\title{
Retrofit de Painéis Elétricos de um Hospital da Região Serrana com adequação à NR-10
}

\author{
Retrofit of Electric Panels of a Hospital of the Serrana Region with adequacy to NR-10. \\ Jose Henrique Moreira Rodrigues ${ }^{\dagger *}$, Alex Franco Ferreira ${ }^{\dagger}$, José Thomaz de Carvalho ${ }^{\dagger}$, Rodrigo de \\ Souza Campista Ferraz
}

Como citar esse artigo. Rodrigues JHM; Ferreira AF; de Carvalho JT; Ferraz RSC. Retrofit de Painéis Elétricos de um Hospital da Região Serrana com Adequação à NR-10. Revista Teccen. 2017 Jul/Dez.; 10 (1): 29-33.

\begin{abstract}
Resumo
O Retrofit é o processo de modernização de algum equipamento já considerado ultrapassado ou fora de norma. $\mathrm{O}$ projeto tem como fundamento a adequação de um painel elétrico de força e comando de uma instalação industrial, com o intuito de normatizá-lo de acordo com a NR 10, que diz respeito à Segurança em Instalações e Serviços em Eletricidade. Para adequação proposta, realizou-se inicialmente um estudo das normas vigentes sobre o tema, elaborou-se então um check-list para levantamento das substituições de equipamentos necessárias e por fim um relatório justificando detalhadamente cada item necessário à substituição. As modificações então realizadas foram executadas visando a segurança e eficiência de energia elétrica das instalações com aplicação da NR 10 e posteriormente a proposta execução do Retrofit foi aplicada à outros painéis de mesmas características e especificações técnicas. Conclui-se que o sistema elétrico do local estudado ficará normatizado de acordo com as Leis Vigentes e conforme a NR 10, trazendo maior segurança, confiança e eficiência. O trabalho serve de referência para aplicação das adequações de forma satisfatória em outros painéis elétricos da mesma organização. Palavras-Chave: NR-10; Retrofit; Painel elétrico.
\end{abstract}

\begin{abstract}
Retrofit is the process of modernizing some equipment already considered outdated or out of standard. The project is based on the adequacy of an electrical panel of force and control of an industrial installation, with the intention of standardizing it in accordance with NR 10, which refers to Safety in Facilities and Services in Electricity. For the proposed adequacy, a study of the norms in force on the subject was initially carried out, a check list was drawn up to collect the necessary equipment replacements and finally a report justifying in detail each item necessary for the replacement. The modifications carried out were carried out aiming at the safety and efficiency of electrical energy of the installations with application of NR 10 and later the proposed execution of Retrofit was applied to other panels of the same characteristics and technical specifications. It is concluded that the electrical system of the place studied will be normalized according to the Laws in force and according to NR 10, bringing greater security, confidence and efficiency. The work serves as reference for the application of adequations satisfactorily in other electrical panels of the same organization.

Keywords: NR-10; Retrofit; Electric pane.
\end{abstract}

\section{Introdução}

Constantemente, diversos profissionais da área de instalações elétricas, sejam eles: eletricistas, técnicos em eletrotécnica, engenheiro eletricista, etc, ficam expostos a painéis elétricos. Caso estes painéis não estejam adequados as normas vigentes de segurança e proteção, aumenta o risco de acidente do trabalho, que se tratando de energia elétrica podem ocasionar danos e prejuízos, como: morte devido ao choque elétrico e paralisação de um processo industrial por falta de energia elétrica.

O projeto tem como fundamento a substituição ou apenas a adequação de todos os painéis elétricos de força e comando de uma empresa com intuito de normatizá-los de acordo com a NR 10 (2004). A Portaria 3.214/78 do Ministério do Trabalho e

Afiliação dos autores: † Universidade Severino Sombra - USS, Vassouras - RJ, Brasil.

* E-mail para correpondência: josehenriquee@hotmail.com 
Emprego, aprova as Normas Regulamentadoras (NRs), relativas a segurança e medicina do trabalho, nelas são descritas as obrigações dos empregadores e empregados. O Retrofit é o processo de modernização de algum equipamento já considerado ultrapassado ou fora de norma, devendo ser criada uma metodologia para realização deste trabalho.

A metodologia utilizada foi realizar estudo das normas vigentes atualizadas referentes as medidas de segurança e produção de painéis elétricos de comando e força, assim como montar um check list de todos os componentes necessários para verificar se estes componentes estão adequados ou não a norma, para verificar a necessidade de troca ou manutenção. Elabora-se então um relatório das necessidades de cada painel separadamente detectando cada problema apresentado e a ação que será tomada para sua adequação ao projeto do retrofit. Este relatório é submetido a uma aprovação dos responsáveis pelo local onde ocorrerá a intervenção, com a apresentação das necessidades de implantação do projeto para a empresa, mostrando os benefícios, tanto para segurança do sistema elétrico da instalação quanto às necessidades das fiscalizações e auditorias futuras. É então criada uma lista de material de cada painel, de acordo com as necessidades para aplicação da NR10 (2004) e normas vigentes. Um pequeno transtorno é gerado devido a necessidade de marcar o agendamento com os responsáveis dos setores, para interrupção momentânea de energia que cada painel alimenta, durante toda a atividade de instalação.

Esse trabalho teve como objetivo avaliar a possibilidade de realização de um retrofit em painéis elétricos em um hospital. Observando a segurança e eficiência de energia elétrica as instalações do cliente com aplicação da NR 10 (2004) em cada painel vistoriado. O sistema elétrico da empresa ficará normatizado de acordo com as Leis Vigentes e conforme a NR 10 (2004), trazendo para a população que ele atende maior segurança. Para a instituição, poderá ser aproveitado como base de metodologia para estudos com este foco em diferentes tipos de processos e equipamentos.

\section{Segurança em instalações elétricas}

Segundo Souza (2013), o uso da eletricidade tornou-se fundamental nas últimas décadas, os avanços no campo da eletricidade têm sido difundidos cada vez mais, entretanto, os casos de acidentes envolvendo a eletricidade também aumentaram.

Infelizmente, ainda têm-se inúmeros acidentes fatais ocorrendo por falta de comprometimento dos empregadores em colocar em prática as prescrições da NR-10/2004. Nesse sentido, uma fiscalização mais efetiva, com uma política de conseqüências reais, é condição intrínseca à mudança do cenário atual (Bizzo, 2013).

Elaborada por meio da portaria do Ministério do Trabalho, $\mathrm{n}^{\mathrm{o}} 3.214$, de 8/6/1978, a NR-10 (2004) sofreu revisão em seu texto, através de um Grupo de Trabalho Tripartite - GTT - designado para este fim e extinto após a entrada em vigor na nova redação dessa norma, publicada no DOU de 8/12/2004. A NR10 (2004) tem como objetivo a implementação de medidas de controle e sistemas preventivos a fim de assegurar a integridade física e a saúde do trabalhador envolvido, direta ou indiretamente, com instalações elétricas e serviços em eletricidade.

De acordo com a NR-10 (2004), as instalações elétricas devem prever as seguintes condições:

- Dispositivos de desligamento de circuitos;

"NR-10 (2004) - Item 10.3.1: É obrigatório que os projetos de instalações elétricas especifiquem dispositivos de desligamento de circuitos que possuam recursos para impedimento de reenergização, para sinalização de advertência com indicação da condição operativa."

- Recursos para impedimento de reenergização;

"NR-10 (2004) - Item 10.3.2: O projeto elétrico, na medida do possível, deve prever a instalação de dispositivo de seccionamento de ação simultânea, que permita a aplicação de impedimento de reenergização do circuito."

- O espaço seguro para acesso aos componentes;

"NR-10 (2004) - Item 10.3.3: O projeto de instalações elétricas deve considerar o espaço seguro, quanto ao dimensionamento e a localização de seus componentes e as influências externas, quando da operação e da realização de serviços de construção e manutenção."

- Proteção contra choque elétrico;

"NR-10 (2004) - Item 10.3.4: O projeto deve definir a configuração do esquema de aterramento, a obrigatoriedade ou não da interligação entre o condutor neutro e o de proteção e a conexão à terra das partes condutoras não destinadas à condução da eletricidade."

"NR-10 (2004) - Item 10.3.5: Sempre que for tecnicamente viável e necessário, devem ser projetados dispositivos de seccionamento que incorporem recursos fixos de equipotencialização e aterramento do circuito seccionado."

- Condições para a adoção de aterramento temporário;

"NR-10 (2004) - Item 10.3.6: Todo projeto deve prever condições para a adoção de aterramento temporário." 
- Projeto elétrico completo com Memorial descritivo com diagramas de proteção;

"NR-10 (2004) - Item 10.3.7: O projeto das instalações elétricas deve ficar à disposição dos trabalhadores autorizados, das autoridades competentes e de outras pessoas autorizadas pela empresa e deve ser mantido atualizado."

"NR-10 (2004) - Item 10.3.8: O projeto elétrico deve atender ao que dispõem as Normas

"Regulamentadoras de Saúde e Segurança no Trabalho, as regulamentações técnicas oficiais estabelecidas, e ser assinado por profissional legalmente habilitado."

"NR-10 (2004) - Item 10.3.9: O memorial descritivo do projeto.

"NR-10 (2004) - Item 10.3.10: Os projetos devem assegurar que as instalações proporcionem aos trabalhadores iluminação adequada e uma posição de trabalho segura, de acordo com a NR 17 (2015) Ergonomia."

\section{Riscos em instalações elétricas}

Conforme Gomes (2013), um princípio que permeia a NR-10 (2004) é o chamado risco elétrico, que pode ser entendido através da definição que a própria norma emprega para "risco": a capacidade de uma determinada grandeza com potencial ou probabilidade de afetar a saúde e a integridade física das pessoas. Desta forma, risco elétrico é a probabilidade de ocorrer danos às pessoas próximas a um sistema elétrico, causado por qualquer um dos fenômenos inerentes à eletricidade. Há diferentes riscos elétricos, mas os principais são o arco elétrico, o choque elétrico e o eletromagnetismo, sendo os dois primeiros os mais danosos aos trabalhadores.

Sobre o arco elétrico, Queiroz e Senger (2012) afirmam que além das queimaduras provocadas pela grande quantidade de energia liberada na forma de calor e alta temperatura, ocorre também a liberação de fumos metálicos e projeção de partículas sólidas. Todos esses efeitos são suficientemente graves para provocar uma lesão permanente ao trabalhador exposto ou leválo a óbito.

De acordo com Barros et al (2012), o acontecimento de um arco elétrico pode trazer graves conseqüências à saúde do trabalhador. A seguir relacionam-se algumas conseqüências e possíveis danos relativos ao arco elétrico:

- Danos visuais devido à radiação ultravioleta e infravermelha; $160 \mathrm{~dB}$;

- Danos auditivos pelo ruído com valores de até

- Queimaduras profundas;
- Traumatismo proveniente de queda;

- Entre outras.

Já o choque elétrico é uma perturbação que ocorre no corpo humano, quando percorrido por uma corrente elétrica e pode ter efeitos diversos. Dependendo do percurso da corrente, intensidade, frequência, bem como da compleição física da vítima, os efeitos do choque elétrico se tornam mais graves. Dentre esses efeitos, enfatiza-se a queimadura interna, fibrilação ventricular e a tetanização, que é a paralisia dos músculos, o que muitas vezes é responsável por o indivíduo não largar a fonte de corrente, agravando ainda mais o choque.

\section{Material e método}

Objetivando atender à prescrições da NR-10, a seguir serão apresentados e comentados os trabalhos feitos, mostrando inicialmente, através de imagens, as condições dos painéis existentes em uma unidade hospitalar. Em seguida, o Check-list elaborado para os painéis. Posteriormente a tabela de verificação das conformidades e não conformidades. Por fim, as imagens dos painéis após os Retrofit com implantação das adequações de acordo com as normas vigentes.

A figura 1, a seguir, registra as condições verificadas através de inspeção visual dos riscos existentes no painel de força do estudo proposto.

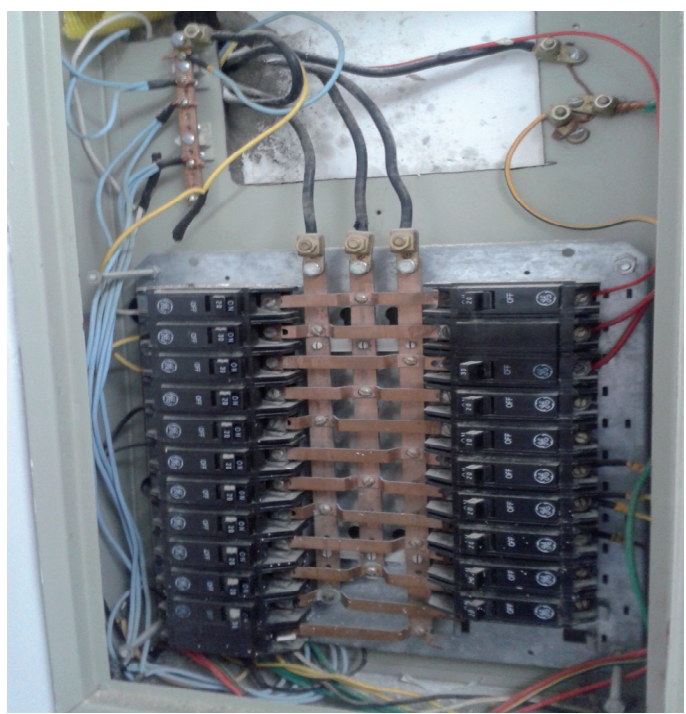

Figura 1. Painel de força antes do Retrofit. Fonte: Autor, 2017.

A figura 2, a seguir, registra as condições verificadas através de inspeção visual dos riscos existentes no painel de comando do estudo proposto. 


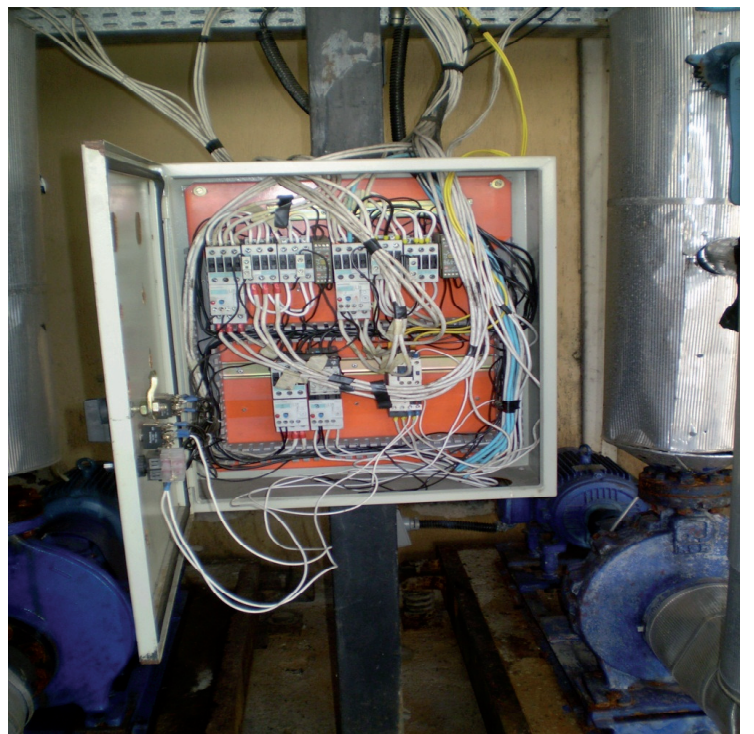

Figura 2. Painel de força antes do Retrofit. Fonte: Autor, 2017.

Com objetivo de evitar falhas no levantamento para o Retrofit, foi elaborado um CheckList que busca ajudar a identificar cada uma das possíveis não conformidades dos componentes e dispositivos elétricos dos painéis. A tabela 1, a seguir, identifica numericamente cada um dos itens analisados no painel, conforme descrição.

A partir do Check-list elaborado, foi criada também uma ficha para registro das não conformidades encontradas. Na ficha elaborada é possível preencher o Nome, Local, Descrição, Observações e Problemas Detectados, de forma a facilitar o registro de todas as informações necessárias para melhor entendimento das intervenções a serem executadas no Retrofit.

Portanto, observa-se que para um adequado Retrofit é necessária uma inspeção visual e testes em busca de identificar todas as intervenções necessárias para elaboração de uma lista de materiais a serem comprados para realização das substituições.

Por fim, foram feitas a instalações previstas em busca do atendimento às normas vigentes e a segurança dos trabalhadores e perfeito funcionamento com componentes elétricos, visando o funcionamento contínuo de todo o processo.

A figura 3, a seguir, mostra o novo painel de comando.

A figura 4, a seguir, mostra o novo painel de força.
Tabela 1. Relação dos itens analisados nos painéis para execução do Retrofit.

\begin{tabular}{|c|c|}
\hline Item & Descrição \\
\hline 1 & Acabamento \\
\hline 2 & Sem Disjuntor Geral \\
\hline 3 & Cabos compatíveis com alimentação \\
\hline 4 & Proteção Acrílico \\
\hline 5 & Emendas não Conformes \\
\hline 6 & Sem identificação dos Circuitos \\
\hline 7 & Limpeza do painel/Reaperto \\
\hline 8 & Divisão de Barramento Terra/Neutro \\
\hline 9 & Fixação do Quadro \\
\hline 10 & Aquecimento Terminal \\
\hline 11 & Aquecimento Barramento \\
\hline 12 & Quadro Exposto ao tempo \\
\hline 13 & Oxidação \\
\hline 14 & Disjuntor em mal estado \\
\hline 15 & Disjuntor Geral não Compatível \\
\hline 16 & Isolador do Barramento \\
\hline 17 & Mais de um circuito por Disjuntor \\
\hline 18 & Crimpar Terminal \\
\hline
\end{tabular}

Tabela 2. Ficha para registro de não-conformidades

\begin{tabular}{|c|l|}
\hline $\begin{array}{c}\text { Número de } \\
\text { Referência }\end{array}$ & 5 \\
\hline Nome & Sem identificação \\
\hline Local & Farmácia \\
\hline Descrição & Sala ao lado direito do banheiro \\
\hline Observações & masculino, $3^{\text {o }}$ andar \\
\hline Problemas & Sem Disjuntor Geral \\
\hline Detectados & Proteção de Acrílico \\
\hline & Acabamento \\
\hline
\end{tabular}




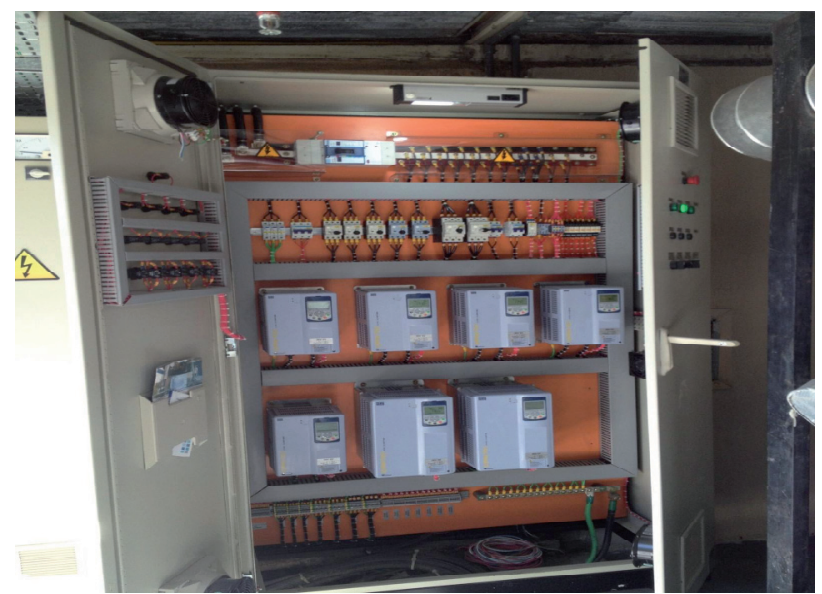

Figura 3. Novo painel de comando. Fonte: Autor, 2017.

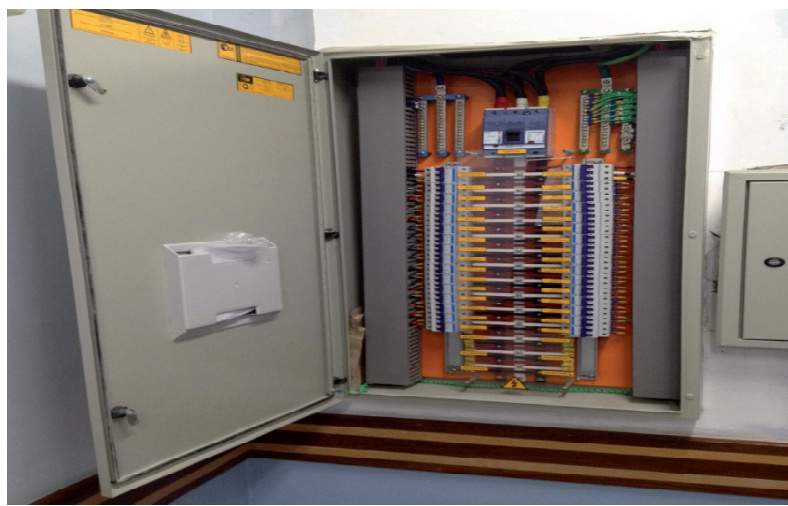

Figura 4. Novo painel de força.. Fonte: Autor, 2017.

\section{Considerações finais e conclusão}

Através deste trabalho de retrofit voltado para as necessidades da NR-10 (2004), foi possível comprovar que sua aplicação é essencial para estabelecer os requisitos e condições mínimas de forma a garantir a segurança e a saúde dos trabalhadores que, direta ou indiretamente, trabalhem com painéis elétricos.

Torna-se então necessária a criação de um sistema estruturado de informações sobre as condições atuais dos painéis elétricos, objetivando averiguar através de inspeções e testes as não conformidades que devem ser tratadas para realizar a prevenção contra acidentes com trabalhadores e falha no fornecimento de energia elétrica devido a problemas em painéis, ainda mais tratando-se da área hospitalar onde o fornecimento de energia elétrica aos equipamentos hospitalares não pode ser interrompido.

A NR-10 (2004) é complementada por: NBRIEC-62271-200, NBR-IEC-60439-1/3, NBR-5410 e NBR-14039. As necessidades da NR-10 devem ser discutidas na fase de projeto e detalhadas no memorial descritivo da obra.É importante ressaltar que aplicações de quadros iguais podem ser inadequadas em situações diferentes, dependendo do tipo de uso ou instalação do quadro.

Conclui-se que este trabalho de retrofit voltado para as necessidades da NR 10 (2004) foi aprovado e está sendo executado em 147 painéis elétricos do hospital. Retrofit voltado a NR 10 (2004) é o processo de modernização de algum equipamento já considerado ultrapassado ou fora de norma, sendo a substituição ou apenas a adequação.

Por fim, fica claro que o sistema elétrico do hospital tornou-se normatizado de acordo com as leis vigentes e conforme a NR 10, trazendo maior segurança, confiança e eficiência.

Para trabalhos futuros recomenda-se a avaliação da aplicação da NR-10 (2004) em supermercados, observando tanto os aspectos de segurança, como de eficiência energética.

\section{Referências bibliográficas}

Barros, B. F. et al. (2012). Guia Prático de Análise e Aplicação da NR10. Editora Érica.

Bizzo, A. (2013). Revista O Setor Elétrico, edição Março.

.NR-10/2004. Norma Regulamentadora 10 - Segurança em instalações e serviços em eletricidade. Texto dado pela Portaria GM n. ${ }^{\circ}$ 598, de 07 de dezembro de 2004.

NR 17/2015 - Ergonomia - de 29 de Setembro de 2015.

.NBR-IEC-62271-200/2007 - Conjunto de manobra e controle de alta tensão parte 200: Conjunto de manobra e controle em invólucro metálico para tensões acima de $1,0 \mathrm{kV}$ até e inclusive $52 \mathrm{kv}$ - edição - 19.03.2007

NBR-IEC-60439-1/3/2003 - Conjunto de manobra e controle de baixa tensão parte 1: Conjuntos com ensaio de tipo totalmente testados (TTA) e conjuntos com ensaio de tipo parcialmente testado (PTTA) edição - 30.06.2003 30.09.2004

NBR-5410/2004 - Instalações elétricas de baixa tensão - edição -

NBR-14039/2005 - Instalações elétricas de média tensão de $1,0 \mathrm{kV}$ a $\overline{36,2 \mathrm{kV}}$ - edição - 31.05.2005.

Gomes, F. M. A. (2013). Análise da conformidade de painéis elétricos com a NR-10: Um estudo de caso realizado em uma subestação industrial. Curitiba/PR. USS. Monografia de especialização de curso de Engenharia de Segurança do Trabalho.

Portaria 3.214/78 do Ministério do Trabalho e Emprego.

Queiroz, A. R. S., \& Senger, E. C. (2012). A natureza e os riscos do arco elétrico, EPIs e Proteção contra Arco Elétrico. [S.1.]: v. 1, ed. 72, p. 46- 51. Disponível em: <http://www.osetoreletrico.com.br/web/a-revista/ fasciculos.html\#acessado em 26/11/2017.>.

Souza, J. A. (2013). Aplicação da norma regulamentador NR-10: Um estudo de caso. Vassouras/RJ. USS. Trabalho final de conclusão de curso de Engenharia elétrica, Vassouras, RJ. 